RESENHA / REVIEW / RESEÑA 

RESENHA DE:

\section{XAVIER, Libânia Nacif. Associativismo docente e construção democrática: Brasil-Portugal (1950-1980). Rio de Janeiro: EDUERJ; FAPERJ, 2013.}

\begin{abstract}
Antes de se tornar o objeto do conhecimento histórico o acontecimento é objeto da narrativa (dos contemporâneos) (RICOEUR, 2008, p. 5).
\end{abstract}

A escolarização da infância, juventude, brancos, negros, índios, pobres, ricos, meninos, meninas - um projeto institucionalizado intensamente a partir do século XIX no Brasil - ainda hoje se legitima e se reinventa. A escola, sua função, seus efeitos e sua apregoada contribuição para o processo de democratização da sociedade são questões constantemente em voga nas pautas sociais e, da mesma forma, discutidas e debatidas pela historiografia brasileira e internacional. Observando arenas em que são tecidos e propostos tais questionamentos, compreende-se a centralidade da figura do professor, sua expressiva participação tanto no processo do fazer educativo quanto nas propostas de reflexão de tal fazer.

A profissão docente, enquanto coletividade, assume mesmo determinado centralismo nas discussões que envolvem as dimensões da construção de identidade dos sujeitos da educação, suas trajetórias, suas intercessões. Nessa direção, o estudo do coletivo e do singular, ou de seus indícios, é fundamental para compreender percursos e narrativas, memórias e marcas, distinções entre o que se vive e a representação de quem narra.

Integrando este conjunto de pressupostos, neste ano de 2013 é lançada a obra Associativismo docente e construção democrática (Brasil-Portugal: 1950-1980), pela EdUERJ. O livro resultou do trabalho desenvolvido pela pesquisadora Libânia Xavier, com apoio institucional do CNPq, da CAPES e da FAPERJ em parceria com pesquisadores e instituições portuguesas - Universidade de Lisboa, Universidade Lusófona.

Pensar o século XX, este passado recente, familiar à maioria de nós, é um desafio que tem sido bastante enfrentado pela historiografia da educação, e é a este desafio que se lança a Professora Associada da Faculdade de Educação da Universidade Federal do Rio de Janeiro, que soma, com este, seu nono livro. Nesta proposta, o desígnio basilar ficou concentrado na análise do associativismo docente na conjuntura do processo de reconstrução democrática na segunda metade dos anos 1900 e, quanto ao recorte espacial, diferente de como se anuncia no título, a opção foi pensar o caso do Rio de Janeiro e Lisboa, mais especificamente.

Sem pecar por uma ingênua generalização, toda obra é feita a partir de recortes, e o caso de associativismo docente não é exceção. Por sua vez, a resenha é uma radicalização do recorte, dada a sua manifestação frequentemente concisa, ao contrário do que aponta a primeira das acepções do Dicionário Houaiss, no qual "resenha" figura como "descrição feita com detalhes, pormenores". Assim, esta intervenção, ao se obrigar a escolher ao máximo o mínimo, vai dar a ver aspectos relacionados à operação realizada, aos vestígios mobilizados, à metodologia empregada. A ideia é pensar menos o objeto e tema desta obra, que a abordagem à qual a mesma esteve submetida nesta narrativa.

Acerca disso, o livro apresenta em sua estrutura a definição, a defesa e o esclarecimento do ponto de vista adotado. Libânia assume seus pressupostos marxistas (p. 19) e as fronteiras que desejou arrostar entre história da educação e sociologia no que tange aos objetos como movimentos sociais, trajetórias, intelectuais, para que fosse possível refletir sobre a "construção social" (p. 17) da profissão que exerce.

O livro considera algumas táticas vestidas por determinados professores com intuito de alargar as margens de autonomia do "grupo" - o conjunto heterogêneo de experiências que é tomado como um coletivo - frente aos acanhamentos e às oportunidades políticas abertas nos processos de reconstrução democrática. Os termos "alguns" e "determinados" se justificam por considerar os limites projetados pelas fontes selecionadas. Neste caso, "sublinhar a singularidade de cada análise é questionar as possibilidades de uma sistematização totalizante" CERTEAU, 2007, p. 32). Inobstante, 
importa salientar que a massa documental operada nesta investigação é interessante e variada, sendo crível, a partir dela (entrevistas e materiais impressos, boletins sindicais, jornais, revistas), acessar opiniões e memórias de alguns protagonistas defensores da militância coletiva, bem como alguns registros de seus opositores (p. 121).

Em sua organização - três seções compostas por oito capítulos, distribuídos em 250 páginas -, a Parte I propõe ressaltar o magistério e suas ações coletivas como objeto de investigação, analisável em sua diversidade, comparável em sua particularidade. Como já salientado anteriormente, os recortes e as seleções são operações comuns; no entanto, Profissão docente: o que dizem os estudos sobre o tema abre a discussão a partir da apresentação de um mapeamento "altamente seletivo" (p. 29) de pesquisas de caráter sócio-histórico. Neste caso, o capítulo destinado a observar a presença e leitura deste tema no campo historiográfico delimita o levantamento e, consequentemente, os resultados obtidos, a partir de seu interesse. O leitor encontra questões atinentes às particularidades da profissão docente e das práticas educativas que anunciavam a dinamicidade do papel dos mestres como sujeitos ativos no processo de construção do caráter profissional do magistério. Dialogando com pesquisas que lançam luz sobre aspectos da identidade, Libânia procura possibilitar a investigação a cerca das mobilizações coletivas, dos protagonismos nos movimentos e manifestações. Em $O$ associativismo docente como objeto de estudo traz à cena escrita ações, greves, manifestações públicas ou protestos, relacionandoos à intenção de visibilidade desse capital simbólico, mas também à reestruturação das relações de poder dentro da escola, de modo que a ação do movimento social possa alterar estruturas e alavancar "possíveis" reconfigurações no sistema político, ensaiando mudanças, experimentando alianças e conquistando direitos. Propondo pensar o problema a partir de ângulos variados, A construção da profissão docente em múltiplos contextos investe em um tipo particular de estudo comparado da história do associativismo docente no Brasil e em Portugal. Embora justifique não estar interessada apenas na "mera identificação das semelhanças e diferenças" (p.81), a análise se apresenta pouco consistente, talvez em razão de uma narrativa repartida ou da massa documental com a qual escolheu operar. Da mesma forma, observa os fenômenos de circulação, negociação e apropriação de ideias, práticas e modelos difundidos nesses cenários. $\mathrm{O}$ esforço foi construído a partir da intenção de dar a ver a contextualização dos processos, cuja proposta é a da observação na perspectiva de escalas variáveis, que se mostra bastante fértil.

Com intento de pensar a ação docente enquanto construção coletiva, a Parte II do livro de Libânia Xavier evidencia um contexto particular de repressão política. Para isso, indica o caráter relacional nas negociações entre forças políticas e sociais, diferentes perspectivas e alguns dispositivos mobilizados no interior deste processo, enquanto reflete acerca de alguns de seus efeitos, ecos e impactos. Em O movimento dos professores do ensino secundário carioca nos anos 1950, pelas lentes da imprensa, a pesquisadora focaliza a reflexão para uma escala mais local. São apresentados resultados de levantamentos realizados nos jornais cariocas de grande circulação sobre o contexto educacional e o movimento docente, apontando, assim, algumas leituras possíveis dos artigos sobre vitórias e derrotas dos sindicatos, memoriais e questões pedagógicas relacionadas ao exercício da profissão. Na variação de escala que propõe a reflexão, alarga-se para pensar essas mesmas manifestações docentes em As greves de 1979 e 1988 no Estado do Rio de Janeiro e as representações construídas nos papéis impressos, a partir deste cenário e por diferentes sujeitos. Em Ação docente em Portugal pós 25 de abril, exercita sua metodologia comparativa, expõe, analisa e reflete acerca da realidade daquele país nos anos 1970. Dialoga com alguns pesquisadores portugueses, fazendo aparecer na escrita os resultados de seus investimentos - ou seja, seu objeto de investigação em outro contexto - sem, no entanto, comparar ou apontar claramente interseções.

O associativismo é o ponto central analisado na Parte III do livro, que pretende dar destaque aos espaços institucionais, eventos, materiais de divulgação e publicação legitimados e mobilizados pelo grupo profissional docente. Em Trajetórias profissionais e militância política, Libânia procurou pensar este coletivo dando voz às experiências, memórias e opiniões individuais (enxugadas, p.177) de professores universitários e da rede pública de educação do Rio de Janeiro, sindicalizados, com atuação nas décadas de 1970 e 1980 (e com a justificativa da disponibilidade, o critério de escolha destes professores se deu pela proximidade que a autora e seu grupo de pesquisa tinham com os mesmos). Da heterogeneidade destes relatos, buscou "estratégias comuns" (p.203) para compor uma "dimensão coletiva da profissão" (p. 203). A educação na história e a história da educação é o último capítulo, erigido com "base na observação das ações e publicações" de outras duas trajetórias particulares em Portugal - Rogério Fernandes (1933-2010) e Rui Grácio (1921-1991). De acordo com Libânia Xavier, a escolha tem como fundamento o fato de ambos terem promovido intensas reflexões acerca da condição, do exercício, da história e da formação docente em Portugal, investindo na "definição de um campo de produção de conhecimento sobre a história da educação" (p.206). Para a pesquisadora, os aspectos sublinhados nas experiências destas "lideranças intelectuais" (p.216) 
permitem ao leitor observar como a produção de conhecimento sobre educação se renova naquele país, com a contribuição dos mesmos.

\section{CONSIDERAÇõES}

Só é possível fazer histórias parciais (VEYNE, 1983, p. 41).

Pensar a ação coletiva dos professores, no Brasil, em Portugal ou em qualquer outro lugar, demanda mobilizar elementos da sua história. E esta história é sempre lacunar, fragmentada, perspectivada. Não é diferente com Associativismo docente que, embora colabore com o campo de interesse na historiografia da educação, apresenta uma série de potencialidades investigativas a serem enfrentadas.

Para muitos, o tema é apaixonante e foi de forma apaixonada que se deu esta escrita, lançada de forma clara, precisa e honesta em relação aos pressupostos, às interlocuções e aos recortes da autora. Talvez por isso, o texto se apresente muitas vezes em um tom de relato de pesquisa, com justificativa dos avanços e lacunas (como é exemplo a página 175 , ou as expressões usadas na página 15, "parcial" e "provisória"). Neste caso, o público leitor pode ser entendido como amplo, não só pelo tema que problematiza e que faz parte de um passado recente ou que diz respeito a toda sociedade, mas porque sua linguagem, não se pretendendo erudita, se caracterizou como leve, de fácil compreensão.

A obra, de um modo geral, esteve voltada menos para o incomum ou complexidades e mais para o que a grega, junta, une professores como um grupo profissional e, da mesma forma, para a "importância da militância política" (p.179) na atividade docente. Com isso, a professora Libânia defende bravamente seu ponto de vista enquanto permite ser observado, por determinados ângulos, um momento da história da educação, da sociedade brasileira e portuguesa de bastante tensão, que deve ser lembrado.

Os casos particulares apresentados na pesquisa são bastante interessantes na medida em que permitem o acesso a diversificados olhares acerca da história. De uma história. De uma história imperfeita - o que não é demérito, visto que, como afirma Antoine Prost (2009, p.211), não há "um método histórico cuja observância viesse a garantir a história perfeita". Desta feita, em tempo greves e manifestações no Rio de Janeiro, nós, professoras públicas, vemos em Associativismo docente e construção democrática um esforço válido de fazer com que a memória e a história não nos deixem esquecer que 0 fazer educativo é um processo, individual e coletivo, em contínua construção.

[...] dia de greve, cerca de cinco mil profissionais da educação participaram da passeata [...]. A passeata começou na Praia de Botafogo e terminou na Estação carioca do metrô, sendo acompanhada por aproximadamente mil policiais militares[...] moradores jogavam papel picado e aplaudiam os manifestantes ("PM joga bomba em professores". Jornal O Dia, 8 de julho de 1988. Capa e p. 2, 3, 22 e editorial).

Uma manifestação de professores da rede municipal de ensino, em greve desde a semana passada, fechou vias importantes da Zona Sul do Rio na tarde desta quartafeira. A Rua São Clemente ficou interditada em toda a sua extensão, a partir da Praia de Botafogo, até as $15 \mathrm{~h}$, porque o protesto terminou em frente ao Palácio da Cidade ("Manifestação de professores interditou vias na Zona Sul do Rio". Jornal O Globo, 14 de agosto de 2013. Manchete eletrônica). ${ }^{1}$

Aline DE Morais Limeira PASChe

Doutoranda em Educação pela Universidade do Estado do Rio de Janeiro (Rio de Janeiro, RJ, Brasil) e Professora de Escola Pública do Rio de Janeiro (Rio de Janeiro, RJ, Brasil). E-mail:<aline.de.morais.pasche@gmail.com>.

CinTIA BoRGES DE ALMEIDA

Mestre em Educação pela Universidade do Estado do Rio de Janeiro (Rio de Janeiro, RJ, Brasil) e Professora de Escola Pública do Rio de Janeiro (Rio de Janeiro, RJ, Brasil). E-mail:<cintiaborgesalmeida@yahoo.com.br>.

\section{REFERÊNCIAS}

CERTEAU, Michel de. A escrita da história. Trad. Maria de Lourdes Menezes. 2. ed. Rio de Janeiro: Forense Universitária, 2007.

PROST, Antoine. Doze lições sobre a história. Rio de Janeiro: Autêntica, 2009.

RICOEUR, Paul. A memória, a história, o esquecimento. Campinas: Editora Unicamp, 2008.

VEYNE, Paul. Como se escreve a história. Trad. António José da Silva Moreira. Lisboa: Edições 70, 1983.

\section{NoTA}

\footnotetext{
1 Disponível em: <http://oglobo.globo.com/rio/manifestacao-de-professoresinterditou-vias-na-zona-sul-do-rio-9520912>.
}

Resenha recebida em setembro de 2013.

Aprovada em janeiro de 2014. 